\title{
A ATUAÇÃO DO PODER JUDICIÁRIO BRASILEIRO DURANTE A PANDEMIA DE COVID-19: IMPACTOS E INOVAÇÕES
}

\section{THE PERFORMANCE OF BRAZILIAN JUSTICE SYSTEM DURING THE COVID-19 PANDEMIC: IMPACTS AND INNOVATIONS}

\section{Karine Jacinto Farias Pacheco da Silva ${ }^{1}$}

Resumo: A pandemia de COVID-19 causou impactos consideráveis sobre todos os setores da sociedade, entre eles saúde, educação, economia, entre outros. A necessidade de distanciamento social visando reduzir a velocidade de disseminação do vírus fez com que os sistemas judiciários do mundo tivessem que se readequar às novas demandas sem deixar de prestar os serviços de acesso à justiça que são direito dos cidadãos. Diante dessa nova realidade mundial, este estudo foi desenvolvido com o objetivo de verificar as alterações na atuação do sistema judiciário brasileiro frente à pandemia de COVID-19. Procedeu-se de uma revisão de literatura com base em estudos nacionais e internacionais. Somente artigos publicados no período de 2016 a 2021 foram considerados elegíveis. Em uma sociedade na qual a informação e as tecnologias fazem parte do cotidiano de pessoas, empresas, governos, enfim, de toda a sociedade, o Poder Judiciário não pode deixar de aderir ao seu uso, pois essas tecnologias representam avanço, garantia de acesso, mesmo em situações de risco para a saúde, agilidade, economicidade e acessibilidade a todos. No Brasil, as inovações vinham sendo lentamente incorporadas e, em face da pandemia, tiveram que ocorrer

1. Bacharel em Direito pela Universidade do Sul de Santa Catarina (Unisul); Especialista em Direito Público pela ESMESC/AMC/FURB; Pós-graduanda em Direito Aplicado pela ESMESC/AMC/FURB; Mediadora de Conflitos do TJSC; Consteladora Familiar e Organizacional pelo Instituto Ipê Roxo; Residente Judicial na $2^{\text {a }}$ Vara Criminal da Comarca de Tubarão - SC. E-mail: karinecartorio@hotmail.com 
repentinamente, trazendo como desvantagem a falta de preparação de muitos servidores para seu uso, porém isso não impede que resultados positivos sejam alcançados.

Palavras-chave: COVID-19. Sistema judiciário. Impactos. Inovações.

Abstract: The COVID-19 pandemic caused considerable impacts on all sectors of society, including health, education, economics, among others. The need for social distance in order to reduce the speed of the spread of the virus meant that the judicial systems of the world had to readjust to the new demands, while remaining the services of access to justice that are the citizens' right. In view of this new global reality, this study was developed with the objective of verifying changes in the performance of the Brazilian judicial system in the face of the COVID-19 pandemic. A literature review was carried out based on national and international studies. Only articles published in the period from 2016 to 2021 were considered eligible. In a society in which information and technologies are part of the daily lives of people, companies, governments, in short, the entire society, the Judiciary cannot fail to adhere to its use, as these technologies represent advancement, guarantee of access even in situations of risk to health, agility, economy and accessibility for all. In Brazil, innovations were slowly being incorporated and in the face of the pandemic they had to happen suddenly, bringing as a disadvantage the lack of preparation of many servers for its use, however, this does not prevent positive results from being achieved.

Keywords: COVID-19. Justice system. Impacts. Innovations.

\section{INTRODUÇÃO}

Os primeiros casos registrados de COVID-19 em Wuhan, na China, foram verificados em dezembro de 2019 como uma pneumonia severa, da qual o agente causador ainda era desconhecido, acometendo trabalhadores do mercado de frutos do mar. Tamanha a capacidade de contágio da doença que esta ultrapassou as fronteiras chinesas e atingiu todos os países do mundo, reconhecida a situação de pandemia em 11 de março de 2020 (SOLTANI et al., 2020, tradução nossa). 
A percepção quanto à rápida disseminação, transmissão comunitária acelerada e gravidade de muitos casos, inclusive conduzindo ao óbito, fez que com os países do mundo adotassem protocolos desenvolvidos de acordo com suas especificidades para reduzir a velocidade de contágio e evitar a sobrecarga dos sistemas de saúde, que ainda não estavam preparados para o atendimento de números expressivos desses casos. Além da falta de conhecimentos sobre a doença, inexistência de protocolo de tratamento efetivo e necessidade de leitos de atendimento intensivo para intubação, muitos sistemas de saúde já vivenciavam situações caóticas e, assim, iniciaram-se os esforços para refrear a transmissão (CASCELLA et al., 2020, tradução nossa).

A transmissão ocorre pelo contato com o vírus, seja de forma direta (de uma pessoa para outra), por gotículas de saliva decorrentes de espirros e tosse, como indireta, por contato com objetos e superfícies contaminados, levando-se as mãos ao rosto, permitindo que o vírus adentre às mucosas. A falta de tratamento exige medidas de prevenção, como distanciamento social, isolamento social (quando possível), higienização constante das mãos e superfícies, além do uso de máscaras (CASCELLA et al., 2020, tradução nossa).

Nesse ínterim, muitos países optaram pelo fechamento dos serviços não essenciais por algum período, outros limitaram o tempo de atendimento e o número de pessoas nos espaços compartilhados. Tais medidas foram consideradas essenciais para reduzir a velocidade com que o vírus se propagava, porém causaram impactos consideráveis em diferentes âmbitos da sociedade, como na educação, na economia etc. (NICOLA et al., 2020, tradução nossa).

Assim como outras áreas, o sistema de justiça sofreu os impactos da pandemia em função da necessidade de proteger cidadãos e equipes de trabalho do risco de contaminação. Os desafios nessa área foram muitos, já que as demandas judiciais são essenciais em grande parcela desses serviços não poderiam ser interrompidos, de modo que outras formas de resolução de conflitos tiveram de ser elaboradas, evitando-se o contato pessoal entre as partes (SOURDIN; LI; MCNAMARA, 2020, tradução nossa). 
Enquanto alguns locais viram as demandas crescer expressivamente, outros verificaram quedas consideráveis. No entanto, em todas as situações, o atendimento às demandas não poderia ser postergado pela falta de conhecimentos quanto ao possível fim da pandemia. Desse modo, os tribunais de justiça de todo o mundo passaram a estudar formas de manter suas atividades, garantindo a segurança dos envolvidos, e os sistemas de resolução virtual passaram a ser aplicados (SOURDIN; LI; MCNAMARA, 2020, tradução nossa).

Diante dessa nova realidade, o presente estudo tem o objetivo de verificar as alterações na atuação do sistema judiciário brasileiro frente à pandemia de COVID-19. Buscou-se compreender quais foram os impactos da pandemia sobre o sistema judiciário brasileiro em função de sua estrutura, recursos e preparação para tal situação, bem como das inovações adotadas.

Um ponto a ser destacado é que, em todo o mundo, as mídias enfatizaram amplamente os impactos da pandemia de COVID-19 sobre os sistemas de saúde, talvez em razão da visibilidade quanto às falhas ocorridas e à falta de leitos, de medicamentos, de profissionais etc. No entanto, o acesso à justiça também foi consideravelmente impactado e, mesmo assim, pouca ou nenhuma atenção foi dedicada a essa situação (SOURDIN; LI; MCNAMARA, 2020, tradução nossa).

A seleção do tema se deu em face de se tratar de uma questão extremamente atual, para a qual nenhuma nação estava preparada, porém levou todos os países a buscarem formas de compreender e atuar adequadamente com as novas limitações e possibilidades em todas as áreas sociais, inclusive na área de justiça.

Procedeu-se de uma revisão de literatura com base em estudos nacionais e internacionais. Para identificar e selecionar os artigos elegíveis, as bases eletrônicas de dados pesquisadas foram: Literatura Latino-Americana e do Caribe em Ciências da Saúde (LILACS), Health Information fromthe National Library of Medicine (Medline), PubMed, Web of Science, Scopus, biblioteca eletrônica Scientific Eletronic Library On-line (SciELO) e Google acadêmico. Somente artigos publicados no período de 2016 a 2021 foram considerados elegíveis. 
Para a busca de artigos, os descritores aplicados foram:

Coronavírus - coronavirus infection;

COVID-19 - COVID-19;

Pandemia - Pandemics; e

Sistema judiciário - Justice system.

Esses termos foram aplicados de forma individual com o intuito de obter dados para esclarecer cada um dos temas, mas também associados (mais de um termo), para identificar quais estudos avaliaram a questão dos impactos da pandemia de COVID-19 sobre o sistema judiciário.

O estudo foi formulado em tópicos visando sua organização e melhor evolução do tema. O primeiro tópico ressalta a COVID-19; o segundo encampa os impactos da pandemia sobre o sistema judiciário no mundo; e o terceiro destaca impactos da pandemia sobre o sistema judiciário no Brasil e os esforços realizados, visando manter sua atuação adequada às demandas sociais. Por fim, são ressaltadas as conclusões alcançadas e as referências consultadas.

\section{COVID-19}

Em dezembro de 2019, foram identificados, em Wuhan, na China, casos de pneumonia de etiologia desconhecida. Como o número de indivíduos com a condição aumentou, estudos para identificar a origem da infecção se intensificaram, e o agente etiológico foi identificado como sendo da família Coronaviridae, gênero Coronavírus (CoV) (GANESH et al., 2021, tradução nossa). Rapidamente, a doença espalhou-se pelo mundo, com início da transmissão comunitária, sem histórico de viagens entre os pacientes contaminados, e foi declarada pandêmica em março de 2020 (SOLTANI et al., 2020, tradução nossa).

Holand, Zaloga e Friederici (2020, tradução nossa) esclarecem que o nome do vírus foi definido em função de seu aspecto com várias espículas, que geram uma imagem microscópica semelhante a coroa solar durante um eclipse. Como ocorre com outros tipos de vírus, o avanço da doença permitiu identificar que novas cepas surgiram, com sintomas 
de adoecimento, fatores de risco e gravidade diferenciados. Os coronavírus são conhecidos de longa data, comuns em diversos mamíferos, mas ao homem tendem a causar apenas uma infecção leve, semelhante a uma gripe. Porém, surtos graves de doenças por coronavírus já foram relatados anteriormente (SALEEM et al., 2020, tradução nossa).

Osurtoatual causaSíndrome RespiratóriaAgudaGrave-Coronavírus-2 (SARS-CoV-2), levando à chamada Doença por Coronovírus-2019 (CoronavirusDisease 2019 - COVID-19) (GANESH et al., 2021, tradução nossa). Deve-se ressaltar que, nos últimos 20 anos, os CoVs causaram epidemias graves no Leste Asiático e no Oriente Médio. Em 2002, ocorreu a Síndrome Respiratória Aguda Grave (SARS). Já, em 2012, foi relatada a Síndrome Respiratória do Oriente Médio (MERS), ambas tendo como agentes etiológicos os coronavírus em cepas específicas (DHAMA et al., 2020, tradução nossa).

Na COVID-19, os sintomas e a gravidade são fatores diretamente influenciados pelo sistema imunológico de cada indivíduo. Pessoas com sistemas imunológicos fortalecidos podem passar pela doença sem sintomas, enquanto aquelas com comprometimentos imunológicos, como idosos, obesos, pessoas com doença renal crônica, problemas cardiovasculares e cardiorrespiratórios, câncer, HIV, entre outras condições, podem evoluir rapidamente para a necessidade de intubação e até mesmo o óbito (STRIZOVA et al., 2021, tradução nossa).

Wilder-Smith e Freedman (2020, tradução nossa) afirmam que o contágio da doença ocorre de modo rápido e fácil, especialmente em ambientes fechados e nos quais há contato direto entre as pessoas sem os devidos cuidados de higiene e uso de máscaras. Nesse sentido, manter o distanciamento social é medida essencial para o controle epidemiológico da condição. $\mathrm{O}$ isolamento dos doentes, ou seja, manter as pessoas acometidas pela condição afastadas das demais, é essencial, porém, como algumas pessoas são assintomáticas (mas seguem transmitindo), evitar o contato social, nesse período, tornou-se a melhor medida preventiva possível. 
Relevantes os esclarecimentos de Brasil, Cavalcante e Cardoso (2020, p. 108) a respeito das medidas de distanciamento social para o controle da propagação da COVID-19, enfatizando que:

A referida doença, apesar da letalidade baixa, atinge rapidamente a milhares de pessoas, originando, em alguns casos, problemas pulmonares graves, sendo necessário a internação hospitalar e o uso de ventiladores pulmonares. Ante a possibilidade de contaminação rápida de pessoas, fez-se necessário o controle da propagação da doença, para que não houvesse um colapso do sistema de saúde, que, por sua vez, não suportaria boa parte da população utilizando os seus serviços no mesmo período de tempo.

Assim, a interrupção de boa parte das atividades ocorridas no contexto social se deu com o foco central no controle da contaminação ou, pelo menos, na redução da velocidade com que isso ocorre.

Outro ponto que merece atenção refere-se ao período de incubação da doença, compreendido entre a contaminação e o início dos sintomas. Quando se tem uma visão específica do período de incubação de uma condição, é possível desenvolver medidas de atenção e prevenção de sua disseminação, porém, no caso da COVID-19, por se tratar de uma doença relativamente recente, os dados ainda são bastante restritos e heterogêneos, com uma variação de 1 a 14 dias. No período inicial dos sintomas, podem parecer outras condições, como resfriados e alergias, e, assim, ocorre a contaminação de outrem sem que o hospedeiro saiba que está colocando outras pessoas em risco, caso não esteja isolado ou afastado do convívio social (ELIAS et al., 2021, tradução nossa).

A pandemia da COVID-19, em 21 de abril de 2021, já havia alcançado 142.557.268 pessoas (casos confirmados), com 3.037.398 óbitos, e 889.827.023 doses da vacina foram administradas em todo o mundo. Do total de casos confirmados, 60.062 .728 ocorreram nas Américas (região com a maior incidência no mundo). No Brasil, são 13.973.695 casos confirmados, com 374.682 óbitos e 32.394 .085 doses da vacina administrada até 21 de abril de 2021 (WHO, 2021).

Diante do exposto, compreende-se que não é possível saber quem são os indivíduos com ou sem risco de estarem contaminados pela CO- 
VID-19, inclusive pelo fato de que muitos sequer apresentarão sintomas. O período de incubação, diferente para cada indivíduo, também altera os padrões de risco de contágio.

Nessa seara, o distanciamento social é uma medida preventiva essencial para a segurança de todos, no entanto com impactos importantes para diferentes setores da sociedade. Neste estudo, o foco recai sobre o sistema judiciário brasileiro em função da necessidade de alteração dos padrões de atendimento presencial e número de pessoas atendidas nos tribunais brasileiros. Porém, considera-se relevante apresentar dados de tal situação no mundo antes de adentrar ao cenário brasileiro.

\subsection{Impactos da pandemia de COVID-19 sobre o sistema judiciário no mundo}

Pandemias são situações nas quais doenças infectocontagiosas ultrapassam as fronteiras de seu local de origem e chegam a diversos territórios no mundo. Muitos países mantêm protocolos de ação em caso de situações de pandemia e, assim, conseguem atuar de forma menos problemática com uma situação semelhante à atual. Todavia, a maioria dos locais não conta com planos emergenciais para tais situações e, desse modo, os impactos foram consideráveis e atingiram todos os setores sociais (WILDER-SMITH; FREEDMAN, 2020, tradução nossa).

Manter serviços essenciais em atuação, sempre prezando pela segurança de todos os envolvidos, deve ser uma preocupação central quando do desenvolvimento de políticas de ação e protocolos voltados para situações pandêmicas. A necessidade de serviços de justiça não se encerra mediante situações de agravos em saúde amplamente disseminados, como o cenário atual. De fato, existem alguns conflitos que se tornam ainda mais comuns nesses períodos, como a violência doméstica e outras condutas ofensivas (BALDWIN et al., 2020, tradução nossa; LIU; ZHANG; WANG, 2021, tradução nossa).

As rotinas diárias de todos os setores da sociedade foram impactadas em decorrência da pandemia de COVID-19, gerando esforços para que opções fossem desenvolvidas e permitissem reduzir os prejuízos 
decorrentes de uma nova realidade de isolamento e/ou distanciamento. Atividades em grupo estão proibidas, especialmente aquelas nas quais os grupos estão em espaços fechados. Dessa forma, muitos serviços, públicos e privados, tiveram que se readequar e encontrar alternativas seguras e efetivas ao mesmo tempo. No âmbito da justiça, o momento atual trouxe consigo diversas limitações para as quais estão disponíveis opções, porém muitas delas desconhecidas e complexas. O intuito é proteger as pessoas que atuam no sistema de justiça, bem como aquelas que recorrem a ele para encontrar soluções em conflitos diversos (MILLER; BLUMSTEIN, 2020, tradução nossa).

Dados apontam que os tribunais pelo mundo se esforçam continuamente para manter os parâmetros de segurança de suas equipes e dos cidadãos, sem que as operações necessárias e atendimentos gerais sejam cancelados ou postergados. Para isso, o cenário mais comum foi a alteração do padrão de atendimento presencial para um atendimento virtual, por meio das ferramentas de informação e comunicação. Ao mesmo tempo em que as instalações físicas são fechadas para evitar a circulação do vírus, atendimentos seguem ocorrendo, porém por meio de reuniões e audiências virtuais. Existem casos de atendimento híbrido, presencial e virtual de acordo com as especificidades de cada tipo de demanda (BALDWIN et al., 2020, tradução nossa).

Os tribunais em todo o mundo tiveram que encontrar formas de seguir com suas atividades, já que o acesso à justiça continua sendo crucial, mesmo durante períodos de pandemia, entretanto tiveram que dar maior atenção a questões como prevenção e saúde de seus colaboradores e de todos os cidadãos que buscam esses serviços. Alguns tribunais já realizavam parte de suas atividades pela metodologia virtual, em rede, enquanto outros centralizavam suas atividades de forma presencial, de modo que os impactos e as dificuldades encontradas foram diferentes em locais diversos (SOURDIN; LI; MCNAMARA, 2020, tradução nossa).

Muito se falou e se fala sobre o direito de acesso à saúde, porém o acesso à justiça também é de valor essencial no período de pandemia, principalmente quando do acesso à justiça depende a garantia de direi- 
tos, como atendimento e serviços de saúde. Na verdade, a ligação entre saúde e justiça é considerável, e não se pode priorizar uma e ignorar outra. Muitas populações menos favorecidas precisam recorrer à justiça para que sejam atendidas de forma adequada e rápida, evitando o agravamento das condições. Contudo, se o sistema judiciário interromper suas atividades, isso não será possível (BHASKAR et al., 2020, tradução nossa; SOURDIN; LI; MCNAMARA, 2020, tradução nossa).

A pandemia da COVID- 19 trouxe consigo inegáveis dificuldades que tiveram que ser conhecidas, compreendidas e avaliadas, para as quais a busca de soluções se tornou ampla e constante e, desse modo, não se pode afirmar que foi uma ocorrência positiva. Relevante destacar, todavia, que se conduziu ao remodelamento cultural, de governança, na área de política, economia, crimes e interações sociais. No entanto, é preciso reconhecer que muitos serviços evoluíram amplamente em face dos desafios decorrentes da situação da pandemia, reavaliaram suas atividades e desenvolveram formas de seguir, realizando-as de modo eficiente, com segurança, pensando nas necessidades e nos direitos da população, como ocorre com os sistemas judiciários de boa parte dos países, que se readequaram a uma realidade virtual (LIU; ZHANG; WANG, 2021, tradução nossa).

No presente, as tecnologias vêm sendo usadas de forma ampla para que se assegure o atendimento das demandas judiciais de todos os cidadãos, porém sem que isso represente impactos para a saúde em função da elevação dos riscos de transmissão da COVID-19. As mudanças para o sistema judiciário foram muitas e, em sua maioria, podem ser mantidas com bons resultados, mesmo quando a pandemia estiver sob controle, elevando a praticidade e a agilidade desses serviços (SOURDIN; LI; MCNAMARA, 2020, tradução nossa).

A necessidade de os sistemas judiciários, em todo o mundo, avaliar as dificuldades existentes e remodelar suas atividades com foco no novo cenário vivenciado atualmente é, sem dúvidas, inquestionável e de grande importância. Porém, os estudos sobre o tema devemencontrar formas de demonstrar que esse acesso garantido tem relação direta também com a saúde para que se amplie a compreensão de que a justiça 
atua em todas as áreas sociais e, desse modo, qualquer área impactada trará resultados para a justiça (BHASKAR et al., 2020, tradução nossa; SOURDIN; LI; MCNAMARA, 2020, tradução nossa).

Assim como impactos foram percebidos nos sistemas judiciários em todo o mundo, o cenário brasileiro também teve que passar por adaptações e mudanças para que o atendimento aos cidadãos pudesse ser mantido.

\subsection{Impactos da pandemia de COVID-19 sobre o sistema judiciário no Brasil}

No momento em que foi declarada a pandemia de COVID-19, todos os países do mundo passaram a direcionar seus esforços para a alteração das atividades na área de saúde, educação, trabalho etc. (SÁ, 2021). Não se pode afirmar que os impactos foram menores ou maiores nas diferentes regiões. O que ocorre é que algumas possuíam estruturas melhores e mais bem preparadas que outras. Em todas as situações, porém, as alterações não ocorreram de forma gradativa; foram imediatas por não haver outro meio de agir diante da pandemia que não se adequar (ANTUNES; FISCHER, 2020, p. 2).

Para Lima e Ramos Neto (2020, p. 23), uma doença infectocontagiosa, com potencial de causar óbitos e que se espalhou rapidamente por todo o mundo, gerou uma crise na área de saúde, assim como em todas as outras áreas sociais, tornando-se a responsável pela necessidade de adoção de medidas rápidas de resposta, inclusive dentro do Poder Judiciário.

Sobre a velocidade e agilidade com que as mudanças ocorreram em todo o mundo, inclusive no Brasil, ressalta-se que:

Uma situação sem precedentes se instaurou, conduzindo a maioria das organizações (públicas e privadas) a pedirem aos seus trabalhadores que trabalhassem remotamente, a partir de casa. Se o risco da COVID-19 não existisse, não haveria uma implementação de práticas de teletrabalho de forma ágil e massiva como a ocorrida (ANTUNES; FISCHER, 2020, p. 2). 
Compreende-se, desse modo, que uma crise na área de saúde fez com que todos os sistemas sociais tivessem que ser repensados e readequados, porém, sem muito tempo para planejamento e implementação das ações, uma resposta imediata foi exigida por uma situação de risco para todos os cidadãos.

De forma semelhante Brasil, Cavalcante e Cardoso (2020, p. 112) enfatizam que a percepção quanto à rápida disseminação da COVID-19 e em face da ocorrência de alguns casos relativamente graves, para os quais o sistema de saúde brasileiro não estava preparado, muitas atividades passaram de presenciais para virtuais, como as atividades do Poder Judiciário. Desse modo, “[...] de forma repentina, sem planejamento ou qualquer investimento prévio, os servidores, estagiários e magistrados tiveram que modificar, abruptamente, sua rotina de trabalho, sem qualquer capacitação para tal. Passando o teletrabalho, que antes era exceção, a regra".

Em face dos riscos envolvidos com a doença, o judiciário também começou a buscar formas de atender às demandas dos cidadãos e garantir o acesso à justiça, ao mesmo tempo em que assegura a proteção dos funcionários e dos cidadãos. Para isso, os atendimentos presenciais foram interrompidos, e a metodologia de telecomunicação entre as partes envolvidas foi a ferramenta encontrada. A conciliação virtual demonstrou ser importante e efetiva, porém o sistema judiciário brasileiro, em sua maioria, não estava completamente equipado e preparado para isso e, consequentemente, o percurso foi longo e segue em construção diariamente (SÁ, 2021).

O Conselho Nacional de Justiça (CNJ, 2020, p. 9-11) procedeu um levantamento junto aos tribunais brasileiros e identificou que $98 \%$ dos tribunais que responderam à pesquisa editaram normas quanto ao trabalho remoto no período de pandemia, o que não ocorreu somente no TJM-MG. Dentre as normas editadas, 64\% não estabeleceram critérios de mensuração/controle de produtividade. Dos 36\% dos órgãos regulamentaram alguma forma de mensuração/controle de produtividade, em $10 \%$ dos casos a normativa aplica-se apenas para servidores e em 3\% se estabeleceu obrigatoriedade para magistrados e servidores da área judi- 
ciária. Antes da pandemia, somente $5 \%$ da força de trabalho dos tribunais participantes atuava em regime de trabalho remoto, atividade que recebeu um acréscimo de $79 \%$, ou seja, atualmente a parcela de $84 \%$ da força de trabalho atua de forma remota, $10 \%$ desses servidores seguem atuando de forma presencial e $6 \%$ tiveram as atividades suspensas em função de incompatibilidade com o trabalho remoto.

Destaca-se que 97\% dos trabalhadores em regime remoto têm acesso à VPN - Virtual Private Network, de modo que conseguem acessar sistemas e rede do órgão no qual atuam. Entre os entrevistados, $41 \%$ afirmam que o acesso é bom, mas medidas corretivas tiveram que ser adotadas para isso, enquanto $47 \%$ afirmam que sequer foi necessário adotar medidas corretivas para o bom funcionamento do sistema, e somente $12 \%$ relatam instabilidade ou lentidão (CNJ, 2020, p. 14).

Em 2019, 84\% dos processos no Poder Judiciário eram eletrônicos, a tramitação eletrônica ocorre em 100\% dos novos casos no TST e 97,7\% nos TRTs; na justiça federal 81,8\% são eletrônicos, percentual que chega a $82,6 \%$ na justiça estadual. Em uma análise de todo o acervo de processos, $27 \%$ ainda encontram-se fisicamente armazenados, somente 13 de 62 tribunais (19\%) declararam um percentual abaixo de $90 \%$ de acervo eletrônico, sendo que, no TJES, 21\% eletrônico;no TJRS, 23\%; no TJMG, 31\%; no TJPA, 38\%; no TJSP, 53\%; TJPE, 62\%; no TJCE 79\%; no TJSC, 84\%; no TRF-1, 37\%; no TRF-5, 86\%; no TJM-SP, 30\%; no TJM-MG57\%; e no TRT-10, 83\% (CNJ, 2020, p. 23).

Arena, Porto e Campos (2020, p. 11) lecionam que:

Direito e tecnologia estão atuando de forma cada vez mais conjunta no cenário mundial e no Brasil já temos iniciativas digitais no Poder Judiciário, a exemplo do Processo Judicial Eletrônico, as quais foram impulsionadas com o estado de calamidade, decorrente da pandemia de Covid-19. Isso porque o avanço da pandemia não pode consistir em barreira para o acesso à justiça e materialização de direitos.

Esses dados demonstram que, mesmo antes da pandemia, havia um esforço para maior utilização dos meios eletrônicos para abertura de processos e acervo destes, ainda que não houvesse sido alcançado um 
cenário de total virtualização. De forma semelhante, Sá (2021) enfatiza que os esforços para inserir as tecnologias de forma cada vez mais comum no Poder Judiciário brasileiro não se iniciaram depois da pandemia. A nova situação, porém, exigiu maior agilidade e efetividade nessa conversão, da característica física para virtual. As iniciativas de uso das tecnologias tiveram que ser aceleradas, pois passaram a se configurar como a alternativa mais rápida e com menores impactos à eficiência que deve ser mantida.

Assim, o cenário de pandemia apenas reforçou um laço entre o direito e a tecnologia que já vinha sendo estabelecido anteriormente.

Em 17 de novembro de 2004, foi aprovada a Emenda Constitucional $\mathrm{n}^{\mathrm{o}} 45$ (chamada de reforma do Poder Judiciário), apresentada pelo Deputado Hélio Bicudo ainda em 1992, ou seja, um prazo de 13 anos para sua tramitação e aprovação. A EC apresentou inúmeras e importantes inovações processuais com razoável duração do processo e celeridade processual. Diante dessas novas exigências, o uso das tecnologias adentrou paulatinamente às atividades do sistema judiciário (LENZA, 2021, p. 776).

No cenário da pandemia, porém, os esforços iniciados em 2004 tiveram que ser aplicados repentinamente. Muitos tribunais postergaram suas audiências, pois havia a ideia de que a situação poderia ser controlada rapidamente. Com o passar dos dias, contudo, ficou evidente que a pandemia seria duradoura. Desse modo, os tribunais tiveram que voltar a realizar suas atividades para evitar prejuízos ainda maiores à população (BRASIL; CAVALCANTE; CARDOSO, 2020, p. 100-101).

Dados apontam que o teletrabalho tem o potencial de aumentar a produtividade e a qualidade dos serviços prestados. Por outro lado, deve-se ressaltar que é exigido dos trabalhadores nesse novo sistema de atuação distante dos tribunais que norteiem suas ações justamente para esses resultados: elevação de produtividade com garantia de qualidade (ANTUNES; FISCHER, 2020, p. 5).

Na concepção de Tela (2020, p. 143), as sessões virtuais atendem às demandas crescentes, o que não vinha sendo possível na sistemática tradicional. As mudanças adotadas estão, nesse sentido, contribuindo 
para que o sistema judiciário obtenha resultados positivos, o que gera maior satisfação dos jurisdicionados, mesmo durante um momento de preocupação e riscos na área de saúde. Buscas à justiça sempre ocorrerão, seja em momento de pandemia ou não, mas, em uma situação como a atual, a resposta precisa ser efetiva para que, além das questões de saúde, não se crie um novo problema, a falta de acesso à justiça, que é direito de todos os cidadãos.

As alterações no Poder Judiciário decorrentes da pandemia de COVID-19 foram inúmeras, implementadas por meio de diferentes esforços, algumas com resultados mais lentos que outras. Entretanto, é essencial destacar que não ocorreram comprometimentos na celeridade, na produtividade e no que tange a busca por presteza e eficiência nesses serviços. As partes das demandas seguem sendo atendidas, todavia o canal é virtual na maioria das vezes. Audiências, quando presenciais, ocorrem sob a manutenção de protocolos criteriosos de segurança (SÁ, 2021).

Tela (2020, p. 144-145), sobre as vantagens das audiências virtuais, cita a não paralização do processo, ao contrário do que ocorreu em muitos serviços por algum tempo, em razão da superação das barreiras geográficas, pois a distância entre as partes não impede a realização da audiência, da acessibilidade, isso porque portadores de necessidades especiais poderão acompanhar a audiência sem maiores dificuldades (alguns aplicativos geram legendas automáticas, por exemplo) ecom economia (eliminam-se os gastos com transporte, alimentação etc.); garantia do distanciamento social necessário; maior equilíbrio entre as partes, sem que uma delas se sinta pressionada pela presença da outra; efetivo aproveitamento de tempo; e ampliação do acesso à justiça.

Nesse ponto, Leal e Pereira (2020, p. 36-37) ressaltam que o papel do próprio juiz se expandiu dentro da pandemia, pois cabe aos magistrados analisar medidas governamentais voltadas ao controle da doença e à oferta de serviços de saúde. Os juízes precisam buscar conhecimentos cada vez mais aprofundados sobre as especificidades científicas da pandemia para que possam tomar as decisões mais adequadas. Tudo isso 
também ocorre pela via virtual, com ampla oferta de dados para análise e compreensão dos magistrados todos os dias.

Para Tela (2020, p. 143), a pandemia é uma situação de crise, porém sua ocorrência fez com que o sistema judiciário do país tivesse que encontrar formas para seguir com suas atividades sem elevar riscos, o que forçou todos os envolvidos a fazerem uso de inovações tecnológicas focadas nesse intuito. Os profissionais envolvidos, habilitados ou não para o uso dessas ferramentas inovadoras, não tiveram opção a não ser se adaptarem rapidamente. Essa adaptação, contudo, seguirá sendo útil mesmo quando a crise pandêmica for resolvida.

Por mais necessária que fosse a interrupção das atividades, servindo como medida preventiva à infecção por COVID-19, o que ocorre é que os servidores não estavam preparados para essa nova realidade. Portanto, por mais modernas e avançadas que sejam as tecnologias disponibilizadas, os desafios foram e ainda são amplos, exigindo que haja preparação das pessoas para seguirem com essas atividades no futuro, conforme Brasil, Cavalcante e Cardoso (2020, p. 112).

O CNJ estabeleceu o plantão extraordinário, definindo que, em todo o território nacional, deveria ocorrer a continuidade do funcionamento do Judiciário, atendendo às demandas nacionais mesmo em um cenário pandêmico. Para isso, é preciso "[...] uniformizar o funcionamento dos serviços judiciários e garantir o acesso à justiça no período emergencial de pandemia; tudo visando ao objetivo macro, qual seja, a prevenção do contágio pelo novo Coronavírus (COVID-19)" (LIMA; RAMOS NETO, 2020, p. 25).

Adotar o regime de teletrabalho foi uma medida essencial para que o isolamento social pudesse ser mantido, sem prejuízo do direito de acesso à justiça em decorrência de uma possível interrupção das atividades do Poder Judiciário. Os procedimentos judiciais foram virtualizados, e esforços para auxílio no uso dos programas informatizados ocorreram, ainda que não dentro de padrões de suficiência. Os resultados obtidos em diferentes tribunais ainda não são aqueles esperados para um alcance total da celeridade processual, masjá se percebe um direcionamento 
adequado e importante, que deverá ser melhorado com o perpassar do tempo (BRASIL; CAVALCANTE; CARDOSO, 2020, p. 112).

De acordo com Arena, Porto e Campos (2020, p. 12), “em tempos de pandemia de Covid-19, a solução tecnológica foi a única alternativa para a continuidade das atividades do Poder Judiciário, antecipando ainda mais a discussão sobre a necessidade da tecnologia no sistema de justiça".

$\mathrm{O}$ acesso à justiça é direito de todos os cidadãos, ainda que o país esteja enfrentando uma situação de pandemia como a atual. Não há que se falar em garantia de direitos em uma nação na qual as pessoas não conseguem acessar ao Poder Judiciário para que conflitos diversos sejam adequadamente resolvidos (SIQUEIRA; LARA; LIMA, 2020, p. 27-28).

Nesse sentido, todos os esforços realizados para a continuidade das atividades do Poder Judiciário durante a pandemia, o uso das tecnologias de informação e comunicação, o teletrabalho e as demais medidas adotadas, além de se configurarem como uma importante inovação a ser ainda mais desenvolvida e utilizada mesmo após o período de distanciamento social, são medidas voltadas para a garantia de direitos dos cidadãos.

Por outro lado, existem desafios que precisam ser ressaltados como pontos que exigem resolução, entre eles, a dificuldade de acesso à internet em determinadas regiões; falta de equipamentos modernos e funcionais para a realização das audiências; falta de espaços específicos, quando necessário; confiança (a falta de conhecimentos sobre as tecnologias pode reduzir sua confiabilidade aos olhos das partes); perda da percepção das emoções que podem auxiliar na mediação em alguns casos; as partes sentem-se mais confiantes pela distância e podem agir de forma abusiva; falta de conhecimentos aprofundados dos servidores, cidadãos, advogados etc. sobre o uso dessas tecnologias; ; instabilidade de acesso, que é uma queixa recorrente em alguns locais (TELA, 2020, p. 145-147).

Os dados elencados deixam evidente que o Poder Judiciário, apesar dos impactos da pandemia, poderá utilizar-se de metodologias e apren- 
dizados para que, no futuro, a celeridade processual torne-se ainda maior, tirando-se o maior proveito das ferramentas tecnológicas existentes atualmente.

\section{CONCLUSÃO}

A pandemia de COVID-19 atingiu todos os países do mundo, gerando um efeito severo sobre a saúde pública das nações, especialmente aquelas com menor disponibilidade de recursos e conhecimento de medidas a serem adotadas em cenários de pandemias. Apesar da importância da manutenção da saúde, o fato é que os litígios não deixam de ocorrer. $\mathrm{O}$ atendimento dessas disputas judiciais não pode ser interrompido sem uma data para retorno, já que não se sabe qual será a duração da pandemia. Desse modo, as tecnologias vêm sendo utilizadas em todo o mundo, assim como no Brasil, como um canal para que a prestação jurisdicional não deixe de ocorrer.

As audiências remotas permitem a audição on-line das partes, ou seja, elas não precisam se apresentar no tribunal para que sejam ouvidas e a audiência validada. Comparando-se com a via tradicional, a audiência remota é eficiente, desde que haja disponibilidade de ferramentas tecnológicas, estabilidade da rede, aceitação e confiança das partes. Com isso, evita-se o risco de contaminação dos envolvidos, sem que deixem de ter suas demandas resolvidas.

Em uma sociedade na qual a informação e as tecnologias fazem parte do cotidiano de pessoas, empresas, governos, enfim, de toda a sociedade, o Poder Judiciário não pode deixar de aderir ao seu uso, pois essas tecnologias representam avanço, garantia de acesso mesmo em situações de risco para a saúde, agilidade, economicidade e acessibilidade a todos. No Brasil, as inovações vinham sendo lentamente incorporadas e, em face da pandemia, tiveram que ocorrer repentinamente, trazendo como desvantagem a falta de preparação de muitos servidores para seu uso, o que não impede que resultados positivos sejam alcançados. 


\section{REFERÊNCIAS}

ANTUNES, Evelize Dias; FISCHER, Frida Marina. A justiça não pode parar?! Os impactos da COVID-19 na trajetória da política de teletrabalho do Judiciário Federal. VerBras Saúde Ocup., v. 45, p. 1-12, out. 2020. Disponível em: https:/www.scielo.br/pdf/rbso/v45/2317-6369-rbso-45-e38.pdf. Acesso em: 19 abr. 2021.

ARENA, Marcela Casanova Viana; PORTO, Ana Cristina dos Santos; CAMPOS, Denice Machado de. Acesso à justiça em tempos de pandemia de COVID-19: uma solução consensual e tecnológica para os conflitos trabalhistas. Revista Cidadania e Acesso à Justiça, v. 6, n. 2, p. 01 - 17, jul./dez. 2020. Disponível em: https://indexlaw.org/index.php/ acessoajustica/article/download/7069/pdf. Acesso em: 20 abr. 2021.

BALDWIN, Julie Marie.et al. Court Operations duringthe COVID-19 Pandemic. American journal of criminal justice: AJCJ, p. 1-16, jul. 2020. Disponível em: https://www.ncbi.nlm.nih.gov/pmc/articles/ PMC7354363/. Acesso em: 11 abr. 2021.

BHASKAR, Sonu.et al. Call for Actionto Address Equityand Justice Divide During COVID-19. Frontiers in psychiatry, v. 11, 559905, dez. 2020. Disponível em: https://www.ncbi.nlm.nih.gov/pmc/articles/ PMC7744756/. Acesso em: 15 abr. 2021.

BRASIL, Clarissa Gonçalves; CAVALCANTE, Juliana Rodrigues Barreto; CARDOSO, Nardejane Martins. A imposição do teletrabalho no poder judiciário do estado do Ceará diante do cenário de pandemia. R. Themis, Fortaleza, v. 18, n. 2, p.95-122, jul./dez. 2020.

CASCELLA, M. et al. Features, Evaluation, and Treatmen of Coronavirus. In: StatPearls. Treasure Island (FL): Stat Pearls Publishing; jan. 2020. Disponível em: https://www.ncbi.nlm.nih.gov/books/ NBK554776/. Acesso em: 29 mar. 2021.

CNJ - Conselho Nacional de Justiça. Avaliação dos impactos da pandemia causada pela COVID-19 nos processos de trabalho dos tribunais. Brasília: CNJ, 2020. Disponível em: https://www.cnj.jus.br/wp-content/uploads/2020/08/Impactos-Covid_V3_19082020.pdf. Acesso em: 18 abr. 2021. 
DHAMA, Kuldeep.et al. Coronavirus disease 2019-COVID-19. Clinical Microbiology Reviews, v. 33, n. 4, p. e00028-20, out. 2020. Disponível em: https://www.ncbi.nlm.nih.gov/pmc/articles/PMC7405836/. Acesso em: 31 mar. 2021.

ELIAS, Christelle.et al. The incubation period of COVID-19: A meta-analysis. International journal of infectious diseases: IJID: official publication of the International Society for Infectious Diseases, v. 104, p. 708-710, mar. 2021. Disponível em: https://www.ncbi.nlm.nih. gov/pmc/articles/PMC7857041/. Acesso em: 7 abr. 2021.

GANESH, Balasubramanian. et al. Epidemiology and pathobiology of SARS-CoV-2 (COVID-19) in comparis on with SARS, MERS: An updated overview of current knowledgeand future perspectives. Clinical epidemiology and global health, v. 10: 100694, p. 1-11, abr./ jul. 2021. Disponível em: https://www.ncbi.nlm.nih.gov/pmc/articles/ PMC7806455/. Acesso em: 1 abr. 2021.

HOLLAND, Michael; ZALOGA, Debra J.; FRIDERICI, Charles S. COVID-19 Personal Protective Equipment (PPE) for the emergency physician. Vis J Emerg Med, v. 19, 100740, p. 1-7, mar. 2020. Disponível em: https://www.ncbi.nlm.nih.gov/pmc/articles/PMC7143707/. Acesso em: 31 mar. 2021.

LEAL, Fernando; PEREIRA, Thomaz. Judiciário, ciência e a pandemia: dois desafios, três papéis. Conjuntura Econômica, p. 36-37, jul. 2020. Disponível em: http://bibliotecadigital.fgv.br/ojs/index.php/rce/article/ view/82813/78802. Acesso em: 19 abr. 2021.

LENZA, Pedro. Direito constitucional esquematizado. 25. ed. São Paulo: Saraiva, 2021.

LIMA, Adriana Sousa; RAMOS NETO, Newton Pereira. Gestão judicial da pandemia COVID-19: o trabalho remoto como regra de funcionamento do poder judiciário. Revista de Política Judiciária, Gestão e Administração da Justiça, Encontro Virtual, v. 6, n. 2, p. 22 - 40, jul./ dez. 2020. 
LIMA, F.R.D.S.; SMANIO, G.P.; WALDMAN, R.L.; MARTINI, S.R. Covid-19 e os Impactos no direito. São Paulo. Grupo Almedina (Portugal), 2020. 9786556270333. Disponível em: https://integrada.minhabiblioteca.com.br/\#/books/9786556270333/. Acesso em: 26 abr. 2021.

LIU, Jianhong; ZHANG, Yan; WANG, Xiaoxiang. Covid-19 and Asian Criminology: Uncertainty, Complexity, and the Responsibility of AJOC Amidst Eventful Times. Asian J Criminol., p. 1-4, mar. 2021;1-4. Disponível em: https://www.ncbi.nlm.nih.gov/pmc/articles/ PMC7917949/. Acesso em: 12 abr. 2021.

MILLER, J. Mitchell; BLUMSTEIN, Alfred. Crime, Justice \&the COVID-19 Pandemic: Toward a National Research Agenda. American jornal of criminal justice: AJCJ, p. 1-10, jul. 2020. Disponível em: https://www.ncbi.nlm.nih.gov/pmc/articles/PMC7343408/. Acesso em: 10 abr. 2021.

NICOLA, Maria.et al. The socio-economic implications of the coronavirus pandemic (COVID-19): A review. International Journal of Surgery, London, England, v. 78, p. 185-193, abr. 2020. Disponível em: https://www.ncbi.nlm.nih.gov/pmc/articles/PMC7162753/. Acesso em: 30 mar. 2020.

SÁ, Acácia Regina Soares de. TJDFT - Tribunal de Justiça do Distrito Federal e dos Territórios. O poder judiciário em tempos de pandemia de COVID-19. 2021. Disponível em: https://www.tjdft.jus.br/institucional/imprensa/campanhas-e-produtos/artigos-discursos-e-entrevistas/artigos/2021/o-poder-judiciario-em-tempos-de-pandemia-de-covid-19-1. Acesso em: 21 abr. 2021.

SALEEM, Hajra. et al. Coronavirus Disease 2019 (COVID-19) in Children: Vulnerableor Spared? A Systematic Review. Cureus, v. 12, n. 5, p. e807, maio, 2020. Disponível em: https://www.cureus.com/articles/ 32331-coronavirus-disease-2019-covid-19-in-children-vulnerable-or-spared-a-systematic-review. Acesso em: 29 mar. 2021.

SIQUEIRA, Dirceu Pereira; LARA, Fernanda Correa Pavesi; LIMA, Henriqueta Fernanda C. A. F. Acesso à justiça em tempos de pandemia e os reflexos nos direitos da personalidade. RFD - Revista da Faculdade 
de Direito da UERJ. Rio de Janeiro, n. 38, p. 25-43, dez. 2020. Disponível em: https://www.e-publicacoes.uerj.br/index.php/rfduerj/article/ view/51382. Acesso em: 18 abr. 2021.

SOLTANI, Jafar. et al. Pediatric coronavirus disease 2019 (COVID-19): An insight from West of Iran. North ClinIstanb, v. 7, n. 3, p. 284-291, maio 2020. Disponível em: https://www.ncbi.nlm.nih.gov/pmc/articles/ PMC7251275/. Acesso em: 1 abr. 2021.

SOURDIN, Tania; LI, Bin; MCNAMARA, Donna Marie. Court innovations and access to justice in times of crisis. Health Policy Technol., v. 9, n. 4, p. 447-453, dez. 2020. Disponível em: https://www.ncbi.nlm.nih. gov/pmc/articles/PMC7456584/. Acesso em: 31 mar. 2021.

STRIZOVA, Zuzana.et al. Principles and Challenges in anti-COVID-19 Vaccine Development. International archives of allergy and immunology, v. 182, n. 4, p. 339-349, fev. 2021. Disponível em: https://www. ncbi.nlm.nih.gov/pmc/articles/PMC7900461/. Acesso em: 6 abr. 2021.

TELA, Alexandre A. F. Audiências virtuais: uma visão advocatícia. In: EPM - Escola Paulista da Magistratura. Paradigmas jurídicos no pós-pandemia. Cadernos Jurídicos, São Paulo, ano 21, n. 55, p. 1-224, jul./ set. 2020. Disponível em: https:/www.tjsp.jus.br/Download/Portal/Coronavirus/material/CadernosJjuridicoEPM.pdf?637543134751991914. Acesso em: 18 abr. 2021.

WHO - World Health Organization. WHO Coronavirus (COVID19) dashboard. 21 abr. 2021. Disponível em: https://covid19.who.int/. Acesso em: 21 abr. 2021.

WILDER-SMITH, A; FREEDMAN, D. O. Isolation, quarantine, social distancing and community containment: pivotal role for old-style public health measures in the novel coronavirus (2019-nCoV) outbreak. Journal of travel medicine, v. 27, n. 2: taaa020, mar. 2020. Disponível em: https://www.ncbi.nlm.nih.gov/pmc/articles/PMC7107565/. Acesso em: 5 abr. 2021. 